\title{
Bullous Mastocytosis Mimicking Congenital Epidermolysis Bullosa
}

\author{
Julio Cesar Salas-Alanis ${ }^{a, b, d} \quad$ Cesar Eduardo Rosales-Mendoza ${ }^{b, c}$ \\ Jorge Ocampo-Candiani ${ }^{d}$ \\ ${ }^{a}$ Basic Science Department, School of Medicine, Universidad de Monterrey, ${ }^{b}$ Dystrophic \\ Epidermolysis Bullous Research Association Mexico (DebRA Mexico A.C.), 'Department of \\ Biochemistry and Molecular Medicine, and ${ }^{\mathrm{d}}$ Department of Dermatology, University \\ Hospital, Universidad Autonoma de Nuevo Leon, Monterrey, Mexico
}

\section{Key Words}

Bullous mastocytosis · Bullous epidermolysis · Darier's sign

\begin{abstract}
A 2-month-old female infant was referred to DebRA Mexico from the Regional Children's Hospital because of a generalized dermatosis from birth characterized by multiple blisters and erosions on the trunk, face and limbs, associated with minor trauma. A skin biopsy showing subepidermal blisters associated with a dermal infiltrate of Giemsa-positive cells and CD117-positive antibody was consistent with the diagnosis of bullous mastocytosis. Treatment with oral antihistamines, topical steroids, and antibiotics was initiated, leading to a remission of the lesions.

(c) 2014 S. Karger AG, Basel
\end{abstract}

\section{Introduction}

Bullous mastocytosis (BM) is an unusual variant of the mast cell disease characterized by widespread bullae as its main cutaneous feature. These are caused by mast cell degranulation, which releases proteases that lead to dermoepidermal separation. We present the case of a 2-month-old female patient who was referred to DebRA Mexico with a diagnosis of epidermolysis bullosa (EB). 


\section{Case Presentation}

A 2-month-old female infant was referred to DebRA Mexico from the Children's Hospital because of generalized erosions, crusts, and blisters $1-5 \mathrm{~cm}$ in diameter on the trunk, face, and limbs (fig. 1). The blisters were associated with trauma, suggesting congenital EB simplex, the reason for referral to DebRA Mexico. The patient presented with a history of these clinical findings from the third week of birth.

On physical examination, brown macules and nodules $1-2 \mathrm{~cm}$ in diameter were observed around the blisters. Darier's sign was observed when the macules and nodules were intentionally rubbed. The oral mucosa was not affected. A blood count, blood chemistry, and liver function tests were normal; a liver ultrasound and CT were also normal, while tryptase levels were elevated $(47.4 \mathrm{ng} / \mathrm{ml})$. A skin biopsy showed a subepidermal blister with an abundant mast cell infiltrate in the dermis with Giemsa stain and CD117-positive antibody, confirming the diagnosis of BM (fig. 2).

Oral cetirizine $0.2 \mathrm{mg} / \mathrm{kg} / \mathrm{day}$, betamethasone valerate cream $0.1 \%$, and topical fusidic acid $20 \mathrm{mg}$ once a day were prescribed. The blisters and ulcers subsided 2 weeks after starting treatment.

\section{Discussion}

Mastocytosis is a group of diseases associated with elevated infiltration of mast cells in tissues [1]. Soter [2] described various forms of skin manifestations, including urticaria pigmentosa, solitary mastocytoma, telangiectasia macularis eruptiva perstans, and diffuse and erythrodermic forms, which also include BM, being the least frequent of these skin manifestations $[1,3]$.

BM is characterized by isolated or grouped blisters from birth that contain a serous/hemorrhagic fluid, leaving hyperpigmented brown macules. Lesions can arise on the scalp, trunk, and the extremities [4], in a manner similar to our patient.

Orkin et al. [5] described two forms of presentations: the neonatal form, with a greater risk of severe complications and extracutaneous involvement, and late onset, which shows minimal extracutaneous involvement but with a better prognosis. The latter was the presentation in our patient.

Mutations in the c-Kit (CD117) gene that encodes KIT, a transmembrane receptor that causes the differentiation, maturation, and proliferation of mast cells, have been detected. A deficiency of the KIT receptor or increased activity of the C-kit gene would cause abnormal proliferation of mast cells [6]. Systemic affection such as hepatomegaly, splenomegaly, lymphadenopathy, and long bone osteolysis may be present [1, 3, 4]. If skin lesions are rubbed, mast cell degranulation is triggered that forms a wheal, a change known as Darier's sign that is pathognomonic of the disease. Blister formation is due to the accumulation of tryptase, a protease that accumulates between the dermis and the epidermis [6]. Diagnosis is clinical and is confirmed by the presence of mast cells in a skin biopsy stained with HE, Giemsa, and CD117 [7].

The differential diagnosis includes EB, IgA bullous disease, bullous pemphigoid, staphylococcal scalded skin syndrome, and incontinentia pigmenti [8].

Kleewein et al. [9] reported a case similar to ours in which a 10-month-old patient was referred to EB-Haus Austria showing widespread blisters, hence the errors of diagnosis that occur in the medical community. 
Treatment for BM consists of reducing the factors that trigger mast cell degranulation. The use of antihistamines and sodium cromoglycate are beneficial in most patients [10]. Topical steroid use can improve the evolution of the lesions. It is important to prevent infections in skin blisters by using topical antibiotics.

Due to the similarity between EB and BM, the latter must be considered in the differential diagnoses of congenital EB, especially in a newborn with scattered blisters and erosions related to trauma or spontaneous appearance.

\section{References}

1 Castells M, Metcalfe D, Escribano L: Diagnosis and treatment of cutaneous mastocytosis in children: practical recommendations. Am J Clin Dermatol 2011;12:259-270.

2 Soter N: The skin in mastocytosis. J Invest Dermatol 1991;96:32S-38S.

- 3 Lee E, Kim M, Kang T, Kim S: Diffuse cutaneous mastocytosis with generalized bullae. Ann Dermatol 2010;22:77-80.

4 Avshalumov K, Pichardo R, Jorizzo J, Sangueza O, Goldenberg G: Bullous mastocytosis: report of a patient and a brief review of the literature. Am J Dermatopathol 2008;30:455-457.

5 Orkin M, Good RA, Clawson CC, Fisher I, Windhorst DB: Bullous mastocytosis. Arch Dermatol 1970;101:547-564.

-6 Walker T, von Komorowski G, Scheurlen W, Dorn-Beineke A, Back W, Bayerl C: Neonatal mastocytosis with pachydermic bullous skin without c-Kit 816 mutation. Dermatology 2006;212:70-72.

-7 Horny H, Valent P: Diagnosis of mastocytosis: general histopathological aspects, morphological criteria, and immunohistochemical findings. Leuk Res 2001;25:543-551.

-8 Tay Y, Kwok Y, Lee Y: Generalized bullous eruption in an infant. Pediatr Dermatol 2005;22:79-81.

-9 Kleewein K, Lang R, Diem A, Vogel T, Pohla-Gubo G, et al: Diffuse cutaneous mastocytosis masquerading as epidermolysis bullosa. Pediatr Dermatol 2011;28:720-725.

10 Torrelo A, Álvarez-Twose I, Escribano L: Childhood mastocytosis. Curr Opin Pediatr 2012;24:480-486. 
Salas-Alanis et al.: Bullous Mastocytosis Mimicking Congenital Epidermolysis Bullosa

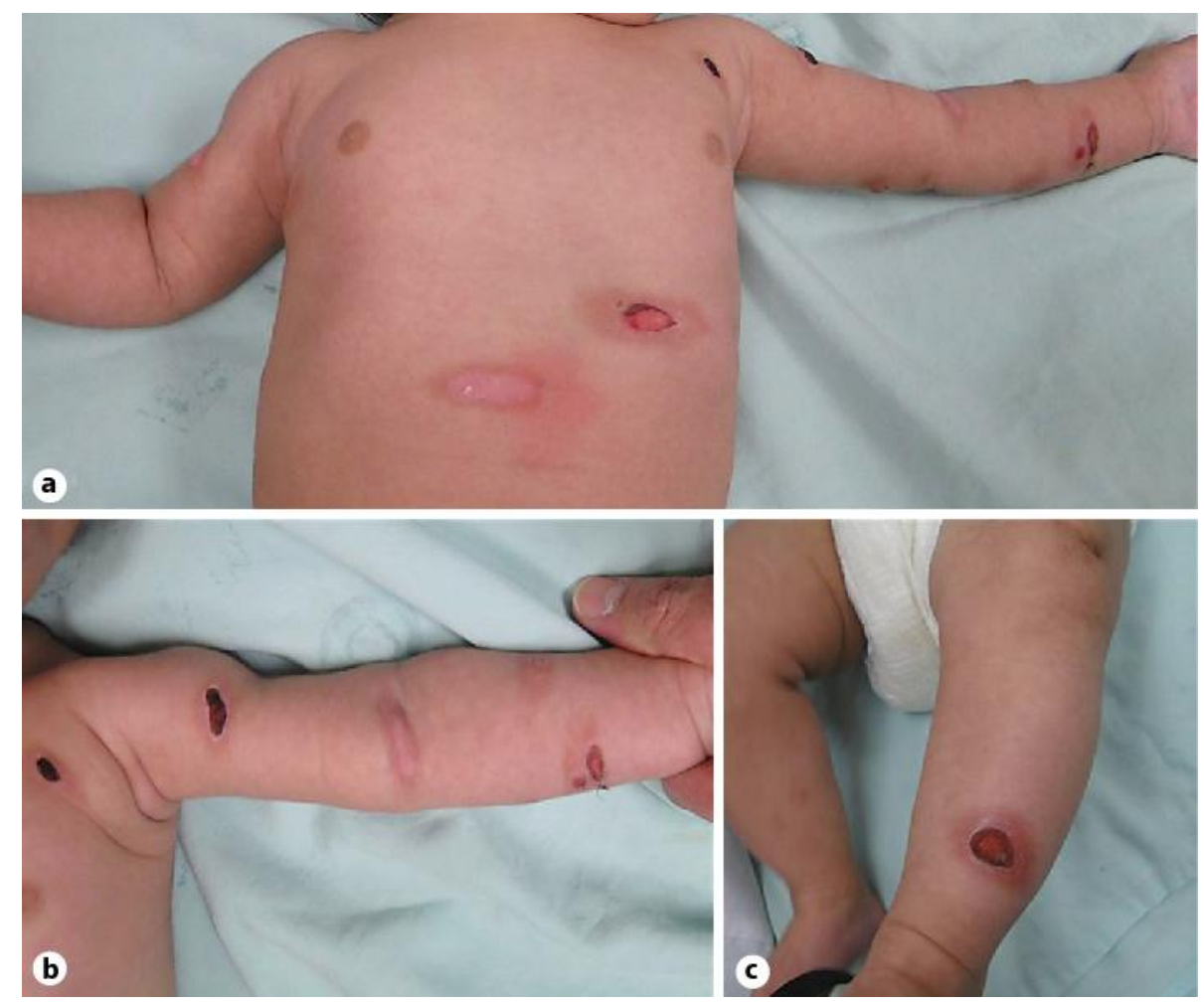

Fig. 1. a Erosions on the chest and left arm. b Hemorrhagic blisters with crusts suggestive of EB. Note the presence of erythema around the maculas after the friction characteristic of Darier's sign. c Ulcer of the left leg, $127 \times 101 \mathrm{~mm}(300 \times 300 \mathrm{DPI})$. 


\section{Case Reports in Dermatology}

(c) 2014 S. Karger AG, Basel www.karger.com/cde

Salas-Alanis et al.: Bullous Mastocytosis Mimicking Congenital Epidermolysis Bullosa

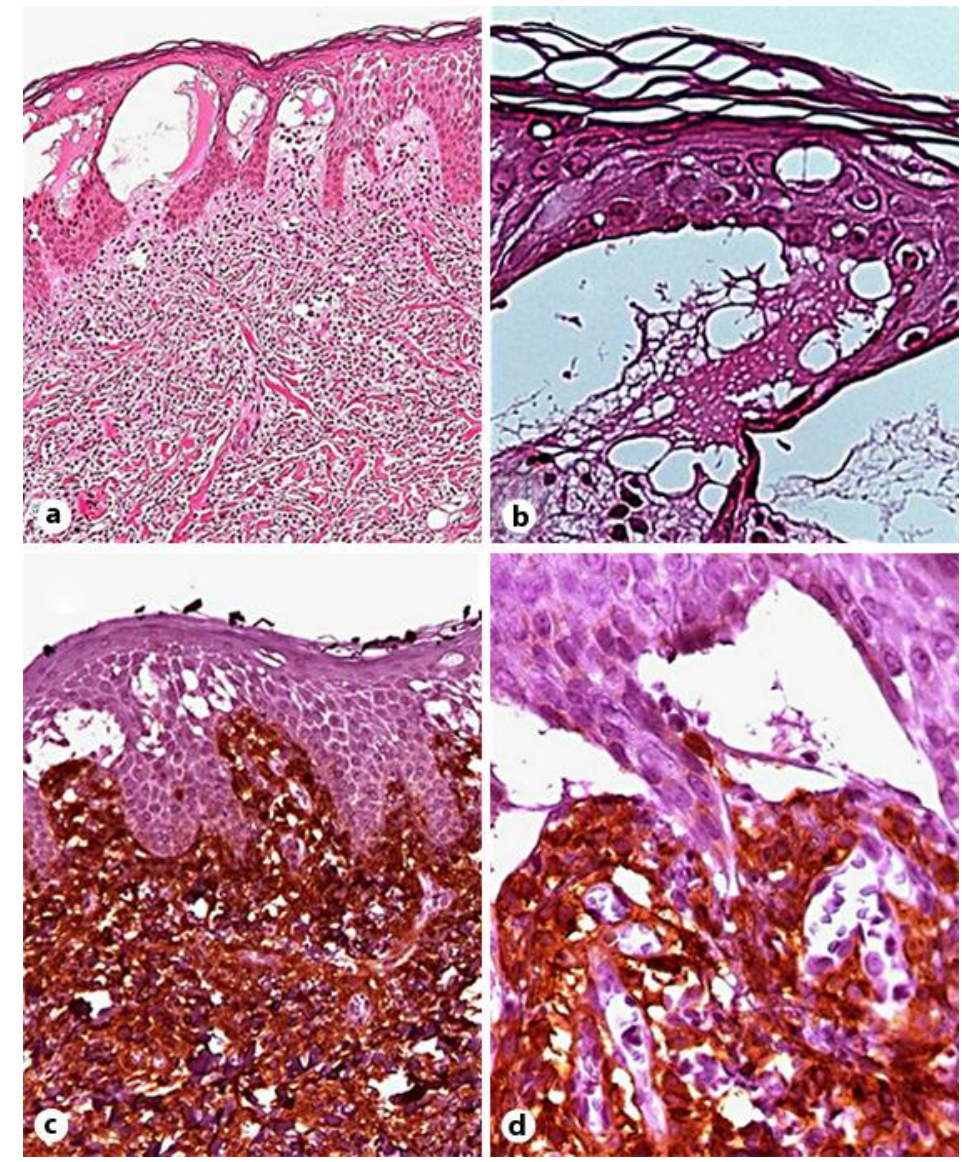

Fig. 2. a Monocellular infiltrates are observed in the papillary and reticular dermis, associated with subepidermal multicenter blisters. HE. $\times 10$. b Subepidermal blister without inflammatory infiltrate. HE. $\times 40$. c CD117-positive infiltrate, dermis cells $(\times 20)$. $\mathbf{d}$ Subepidermal blister associated with CD117-positive mast cells $(\times 40) .106 \times 127 \mathrm{~mm}(300 \times 300 \mathrm{DPI})$. 